\section{Commentary: Progesterone the protector?}

\author{
Matthew C. Henn, MD, and Marc R. Moon, MD
}

Neurodevelopmental delay and deficits remain among the most feared consequences of surgery in children with cyanotic congenital heart disease. With improving survival rates of surgical correction and palliation has been an increasing focus on neurodevelopmental outcomes - particularly because the majority of these children are expected to survive to adulthood. ${ }^{1,2}$ Whereas most previous investigations have targeted the surgical contributions to neurodevelopmental outcomes, Lui and colleagues $^{3}$ provide a refreshing and novel experimental model exploring the potential neuroprotective effects of progesterone on brain development.

The authors clearly identify a mechanism for poor neurologic outcomes in cyanotic heart disease and eloquently identify and explore a therapeutic intervention to potentially reverse the insult. The investigation is thorough, exploring the effects of progesterone at the gross pathological level down to the subcellular level, and the results are promising. By comparing 3 groups (control, hypoxia, and hypoxia with progesterone), the authors were able to demonstrate that chronic hypoxia significantly increases the size of the ventricles, increases white matter loss, and is associated with lower brain weights and worse performance on Rotarod experiments (evaluating motor skill and coordination) compared with controls. Remarkably, all these effects were significantly mitigated with the daily administration of progesterone. These beneficial effects of progesterone were also redemonstrated at the cellular level by showing a significant increase in the number of mature oligodendrocytes and increased myelin basic protein expression. Furthermore, the authors identified a potential mechanism of protection by confirming that progesterone significantly increased the levels of the anti-inflammatory microglia phenotype M2.

Other groups have recently evaluated the neuroprotective benefits of progesterone, and their results are similarly

\footnotetext{
From the Division of Cardiothoracic Surgery, Washington University School of Medicine, St. Louis, Mo.

Disclosures: The authors reported no conflicts of interest.

The Journal policy requires editors and reviewers to disclose conflicts of interest and to decline handling or reviewing manuscripts for which they may have a conflict of interest. The editors and reviewers of this article have no conflicts of interest.

Received for publication April 16, 2020; revisions received April 16, 2020; accepted for publication April 16, 2020; available ahead of print May 11, 2020.

Address for reprints: Marc R. Moon, MD, Cardiac Surgery, Washington University

School of Medicine, 4566 Scott Ave, Campus Box 8234, St Louis, MO 63110

(E-mail: moonm@wustl.edu).

J Thorac Cardiovasc Surg 2020;160:e67

$0022-5223 / \$ 36.00$

Copyright (c) 2020 by The American Association for Thoracic Surgery

https://doi.org/10.1016/j.jtcvs.2020.04.123
}
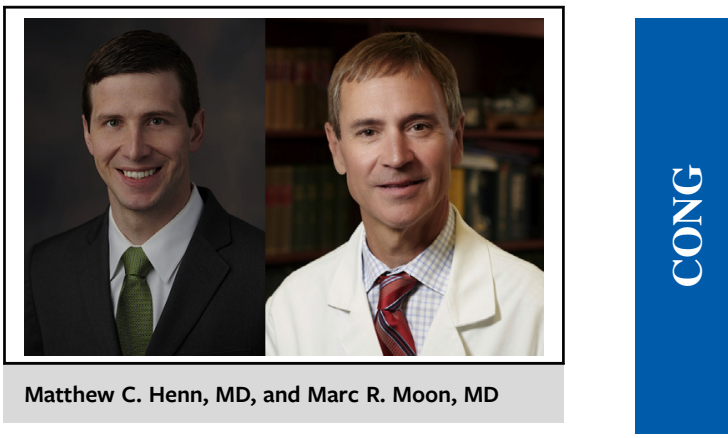

promising. Fabres and coinvestigators ${ }^{4}$ recently studied the effects of progesterone administration before, during, and after hypoxia. Importantly, they demonstrated that progesterone reduces the loss of brain tissue, reduces activity of apoptotic enzymes, and reduces reactive gliosis when administered at all 3 time points.

Although the results of this study and others are promising, we are still far from clinical applicability. Many questions remain unanswered: is it safe, when and how long should it be given, and perhaps most importantly, are the results reproducible in man. The difficulty in answering these questions lies in the challenges in experimental design of testing it in humans. In particular, outcome measures of gliosis, apoptosis, microglial phenotype, and white matter loss are extremely challenging if not impossible to assess clinically. Nonetheless, the authors should be commended on their well-designed study, and their promising results have paved the way for further investigation.

\title{
References
}

1. Marelli A, Miller SP, Marino BS, Jefferson AL, Newburger JW. Brain in congenital heart disease across the lifespan: the cumulative burden of injury. Circulation 2016;133:1951-62.

2. Rettenmaier LA, Kirby PA, Reinking BE, Viaene AN, Hefti MM. Neuropathology of congenital heart disease in an inpatient autopsy cohort, 2000-2017. J Am Heart Assoc. 2020;9:e013575.

3. Liu G, Yan Y, Shi B, Huang J, Mu H, Li C, et al. Benefits of progesterone on brain immaturity and white matter injury induced by chronic hypoxia in neonatal rats. J Thorac Cardiovasc Surg. 2020;160:e55-66.

4. Fabres RB, Montes NL, Camboim YM, de Souza SK, Nicola F, Tassinari ID, et al. Long-lasting actions of progesterone protect the neonatal brain following hypoxiaischemia. Cell Mol Neurobiol. March 13, 2020 [Epub ahead of print]. 